\title{
Supporting Optimal Growth in Infants with Chronic Conditions: How Are We Doing and What Can We Do?
}

\author{
Christopher Smith
}

Keywords: chronic conditions, nutritional interventions, acquired growth failure, infant growth

$\mathbf{S}$ UPPORTING OPTIMAL GROWTH in infants with chronic conditions has never been so important. Outcomes for many chronic conditions, such as cystic fibrosis (CF), necrotizing enterocolitis (NEC), and congenital heart disease (CHD), are improving, but undernutrition remains an all too common problem. Current challenges in treating patients with chronic conditions include the prioritization of breastfeeding, identification of the most effective nutritional interventions, and the prevention or recovery of acquired growth failure.

\section{Cystic Fibrosis}

Over the past 3 decades, the median age of survival for patients with $\mathrm{CF}$ has risen from $\sim 29$ to 43 years. ${ }^{1}$ Clinical outcomes, such as weight gain, have also been steadily improving. These improvements are, in part, due to a combination of new therapies for $\mathrm{CF}$ and the implementation of newborn screening programs. ${ }^{2}$ The recent identification of small-molecule therapies, such as ivacaftor, that target specific mutations in the $\mathrm{CF}$ transmembrane conductance regulator gene is also associated with improved nutritional status, possibly due to a reduction in energy expenditure, reduced gut inflammation, and an increase in fat intake and absorption. 3,4 Despite these advances, the prevalence of undernutrition remains unacceptably high in infants with $\mathrm{CF}$, and improvements in weight and, in particular, length have stagnated in recent years (Fig. 1). ${ }^{1,2}$ The impact of undernutrition during infancy in $\mathrm{CF}$ patients has been shown to have negative longterm effects, including poorer growth, worse lung function, and more severe chest abnormalities at 12 years of age.,6 Breastfeeding can support optimal growth in infants with $\mathrm{CF}$ and is associated with fewer exacerbations and reduced risk of Pseudomonas aeruginosa infection. ${ }^{2,7,8}$ However, breastfeeding rates are low for infants with $\mathrm{CF}$, and most of these infants receive formula as the primary source of nutrition or as a supplement to breastfeeding (Fig. 2). ${ }^{1}$ Parents may choose not to breastfeed due to the overarching urgency to improve weight and a lack of confidence that breast milk can support good growth. Stress from the diagnosis may also factor into the decision or the success of breastfeeding. Furthermore, infants requiring surgery (e.g., stoma formation) will have different nutritional needs and may experience periods of static growth. Multiple nutritional interventions may be required to support optimal growth in infants with $\mathrm{CF}$, such as parenteral nutrition and specialized formulas.

\section{Necrotizing Enterocolitis}

Nutrition also plays a crucial role in the management of NEC. Breast milk contains a variety of factors that may be protective against NEC, such as immunoglobulins, prebiotics, bioactive proteins, and growth factors. For patients requiring surgical intervention post-NEC, breast milk is preferred for enteral feeds after surgery; ${ }^{9}$ however, a recent retrospective analysis of infants aged $<6$ months who underwent intestinal

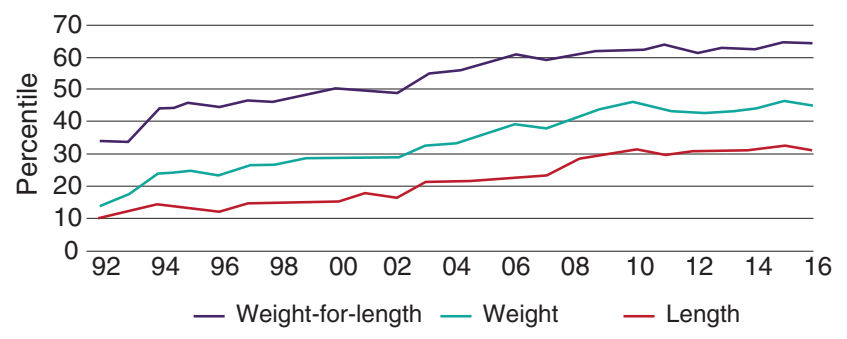

FIG. 1. Median WHO nutritional outcome percentiles for infants aged $<24$ months with $\mathrm{CF}{ }^{1} \mathrm{CF}$, cystic fibrosis. Source of data: Cystic fibrosis patients under care at CF Foundationaccredited care centers in the United States, who consented to have their data entered. Cystic Fibrosis Foundation Patient Registry 2017 Annual Data Report, Bethesda, Maryland (C)2018 Cystic Fibrosis Foundation.

\footnotetext{
Department of Nutrition and Dietetics, Royal Alexandra Children's Hospital, Brighton, United Kingdom.
}

(C) Christopher Smith, 2019; Published by Mary Ann Liebert, Inc. This Open Access article is distributed under the terms of the Creative Commons License (http://creativecommons.org/licenses/by/4.0), which permits unrestricted use, distribution, and reproduction in any medium, provided the original work is properly cited. 


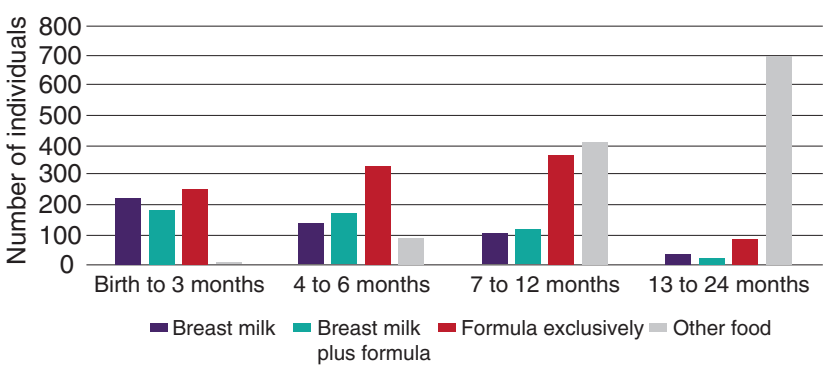

FIG. 2. Form of feeding by age in infants with $\mathrm{CF}^{1}$ Source of data: Cystic fibrosis patients under care at $\mathrm{CF}$ Foundationaccredited care centers in the United States, who consented to have their data entered. Cystic Fibrosis Foundation Patient Registry 2017 Annual Data Report, Bethesda, Maryland (C)2018 Cystic Fibrosis Foundation.

surgery reported that infants with NEC received breast milk in only $7 \%$ of hospitalized days. ${ }^{10}$ If breast milk is not available or the patient is intolerant to standard preterm formulas, hydrolyzed formulas (e.g., semielemental and amino acid based) may be used, but there is limited evidence on which type is best for infants recovering from NEC. ${ }^{9,11}$ Feeding strategies should aim to support growth, encourage adaption, and prevent parenteral nutrition-associated liver disease, yet the perfect nutrition to support optimal growth may not always be clear. Although breast milk is recommended, breastfeeding may be very difficult due to stress, loss of confidence, and other negative psychological effects parents experience when their infant is hospitalized in the neonatal intensive care unit (NICU). ${ }^{12}$

\section{Congenital Heart Disease}

Mortality associated with CHD has been declining, yet the prevalence of growth restriction in infants and young children with CHD has remained at $\sim 20 \%$ since the 1960 s, despite advances in research, methodology, education, and feeding strategies. ${ }^{13,14}$ Poor growth in infants with CHD can result in more frequent hospitalizations, poorer surgical outcomes, and higher rates of mortality, as well as long-term adverse effects such as cognitive impairment and persistent growth retardation. ${ }^{15,16}$ Similar to other chronic conditions, challenges in treating infants with CHD include supporting breastfeeding and appreciating the infant's limitations. Infants with cardiac conditions are unpredictable, unstable, and unique; the return to optimal growth can be long and associated with consequences.

In summary, breastfeeding has a pivotal role in treating chronic diseases, yet it can be challenging due to the medical and emotional complexities associated with these conditions. Parents experience stress with diagnosis and having a child in the NICU. They also face pressures from the wider multidisciplinary team to prevent growth failure and may lose confidence in their ability to maintain or promote growth with breast milk. Furthermore, infants with chronic conditions have inherent absorption/malabsorption issues and additional nutritional requirements. Dietitians and nutritionists must work to balance these issues to support optimal growth in all of these vulnerable patient groups.

\section{Disclosure Statement}

C.S. has received speaker fees for lectures from Danone, Nutricia, Prolacta, and Nestle.

\section{References}

1. Cystic Fibrosis Foundation. Patient Registry 2017 Annual Data Report. Available at https://www.cff.org/Research/ Researcher-Resources/Patient-Registry/2017-Patient-RegistryAnnual-Data-Report.pdf (accessed March 11, 2019).

2. Leung DH, Heltshe SL, Borowitz D, et al. Effects of diagnosis by newborn screening for cystic fibrosis on weight and length in the first year of life. JAMA Pediatr 2017;171: 546-554.

3. Bosch B, De Boeck K. Searching for a cure for cystic fibrosis. A 25-year quest in a nutshell. Eur J Pediatr 2016;175:1-8.

4. Stallings VA, Sainath N, Oberle M, et al. Energy balance and mechanisms of weight gain with ivacaftor treatment of cystic fibrosis gating mutations. J Pediatr 2018;201:229-237.e4.

5. Sanders DB, Fink A, Mayer-Hamblett N, et al. Early life growth trajectories in cystic fibrosis are associated with pulmonary function at age 6 years. J Pediatr 2015;167: 1081.e1-1088.e1.

6. Sanders DB, Zhang Z, Farrell PM, et al. Early life growth patterns persist for 12 years and impact pulmonary outcomes in cystic fibrosis. J Cyst Fibros 2018;17:528-535.

7. Jadin SA, Wu GS, Zhang Z, et al. Growth and pulmonary outcomes during the first $2 y$ of life of breastfed and formula-fed infants diagnosed with cystic fibrosis through the Wisconsin Routine Newborn Screening Program. Am J Clin Nutr 2011;93:1038-1047.

8. Hoen AG, Li J, Moulton LA, et al. Associations between gut microbial colonization in early life and respiratory outcomes in cystic fibrosis. J Pediatr 2015;167:138-147.e1-e3.

9. Christian VJ, Polzin E, Welak S. Nutrition management of necrotizing enterocolitis. Nutr Clin Pract 2018;33:476-482.

10. Varma S, Bartlett EL, Nam L, et al. Use of breast milk and other feeding practices following gastrointestinal surgery in infants. J Pediatr Gastroenterol Nutr 2019;68:264-271.

11. Embleton ND, Zalewski SP. How to feed a baby recovering from necrotising enterocolitis when maternal milk is not available. Arch Dis Child Fetal Neonatal Ed 2017;102: F543-F546.

12. Al Maghaireh DF, Abdullah KL, Chan CM, et al. Systematic review of qualitative studies exploring parental experiences in the Neonatal Intensive Care Unit. J Clin Nurs 2016;25:2745-2756.

13. Feldt RH, Strickler GB, Weidmann WH. Growth of children with congenital heart disease. Am J Dis Child 1969; 117:573-579.

14. Costello CL, Gellatly M, Daniel J, et al. Growth restriction in infants and young children with congenital heart disease. Congenit Heart Dis 2015;10:447-456.

15. Daymont C, Neal A, Prosnitz A, et al. Growth in children with congenital heart disease. Pediatrics 2013;131:e236-e242.

16. Ravishankar C, Zak V, Williams IA, et al. Association of impaired linear growth and worse neurodevelopmental outcome in infants with single ventricle physiology: A report from the pediatric heart network infant single ventricle trial. J Pediatr 2013;162:250-256.e2.

Address correspondence to: Christopher Smith, SRD Department of Nutrition and Dietetics Royal Alexandra Children's Hospital BN2 5BE Brighton United Kingdom

E-mail: chris.smith53@nhs.net 